\title{
CORRECTION 2
}

To the article "Modulation of Galactic Cosmic Rays Due to Magnetic Clouds and Associated Structures in the Interplanetary Space: 1996-2018,”by M. Fadaaq and B. Badruddin, Vol. 64, No. 2, pp. 210-218, June, 2021

Due to a typesetting error, the figures and table are missing from the paper. The figures and table follow:

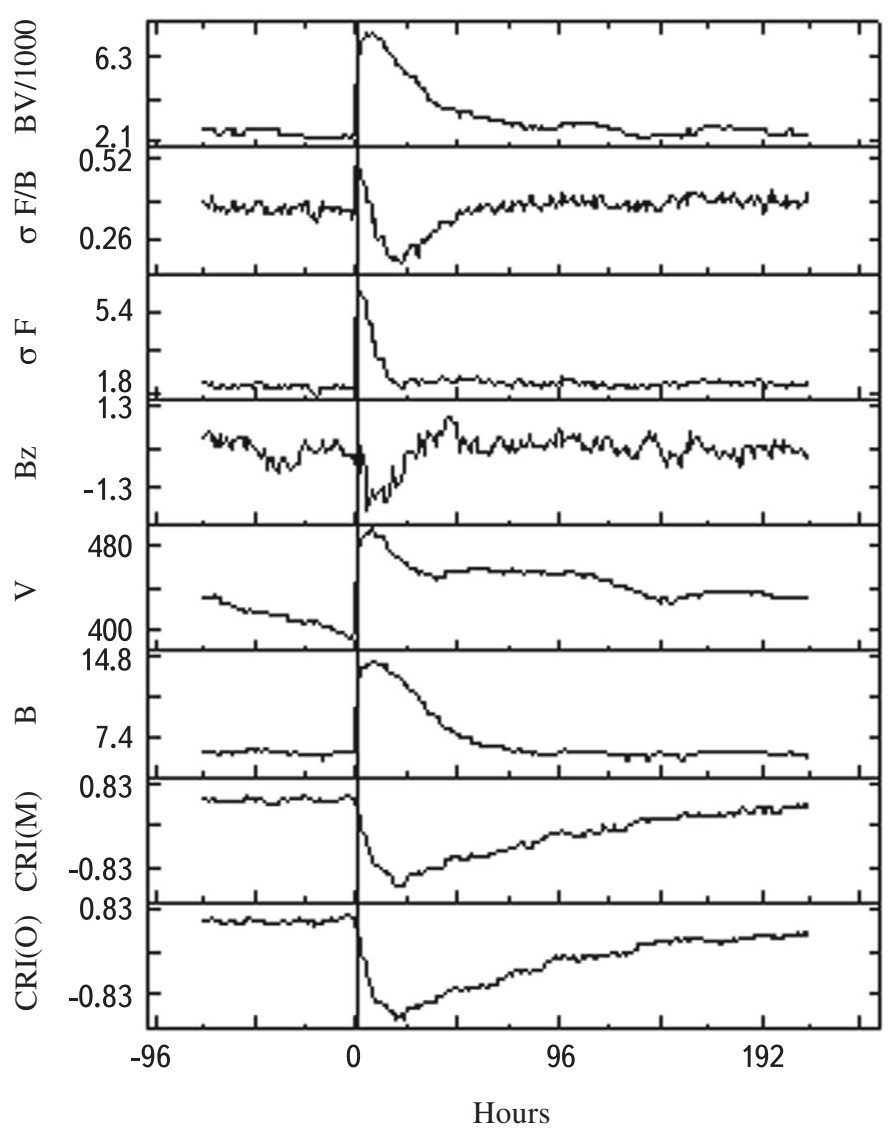

Fig.1a. Superposed epoch analysis results of hourly neutron monitor data of Oulu $[\mathrm{CRI}(\mathrm{O})(\%)]$ and Moscow [CRI(M) (\%)] stations, magnetic field [B (nT)], solar wind velocity $\left[\mathrm{V}\left(\mathrm{km} \mathrm{s}^{-1}\right)\right]$, north-south component of magnetic field $[\mathrm{Bz}(\mathrm{nT})]$, sigma in magnetic field vector [Sigma $\mathrm{F}(\mathrm{nT})]$, normalized Sigma F [SigmaF/B] and interplanetary electric field $[\mathrm{BV} / 1000(\mathrm{mV} / \mathrm{m})]$ during the passage of shockassociated magnetic clouds observed in solar cycle 23\&24 (1996-2018); Epoch (zero time) corresponds to start time of shock. 


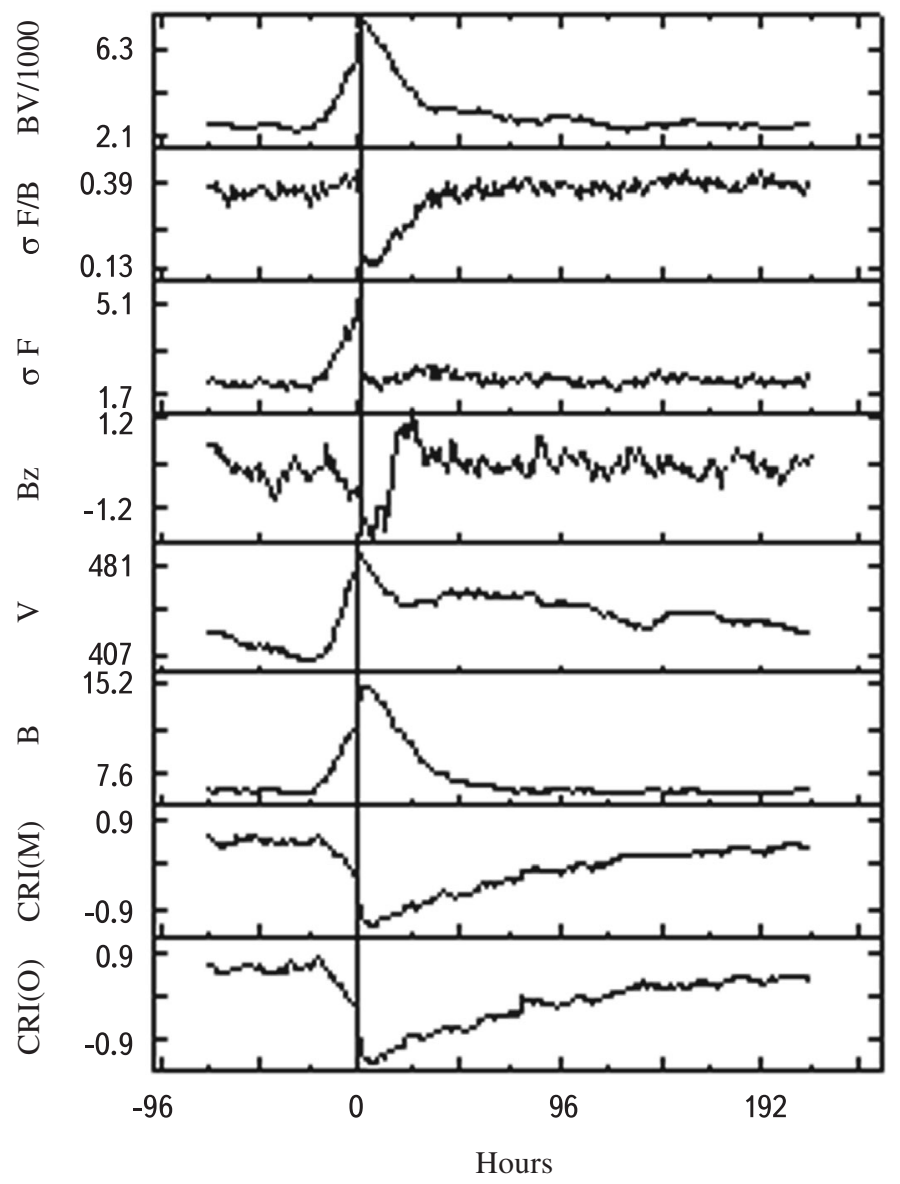

Fig.1b. Superposed epoch analysis results of hourly neutron monitor data of Oulu [CRI(O) $(\%)]$ and Moscow [CRI(M) (\%)] stations, magnetic field [B $(\mathrm{nT})]$, solar wind velocity [V $\left.\left(\mathrm{km} \mathrm{s}^{-1}\right)\right]$, north-south component of magnetic field $[\mathrm{Bz}(\mathrm{nT})]$, sigma in magnetic field vector [Sigma $\mathrm{F}(\mathrm{nT})]$, normalized Sigma F [Sigma F/B] and interplanetary electric field $[\mathrm{BV} / 1000(\mathrm{mV} / \mathrm{m})]$ during the passage of shockassociated magnetic clouds observed in the solar cycle 23\&24 (1996-2018); Epoch (zero time) corresponds to start time of MCs. 


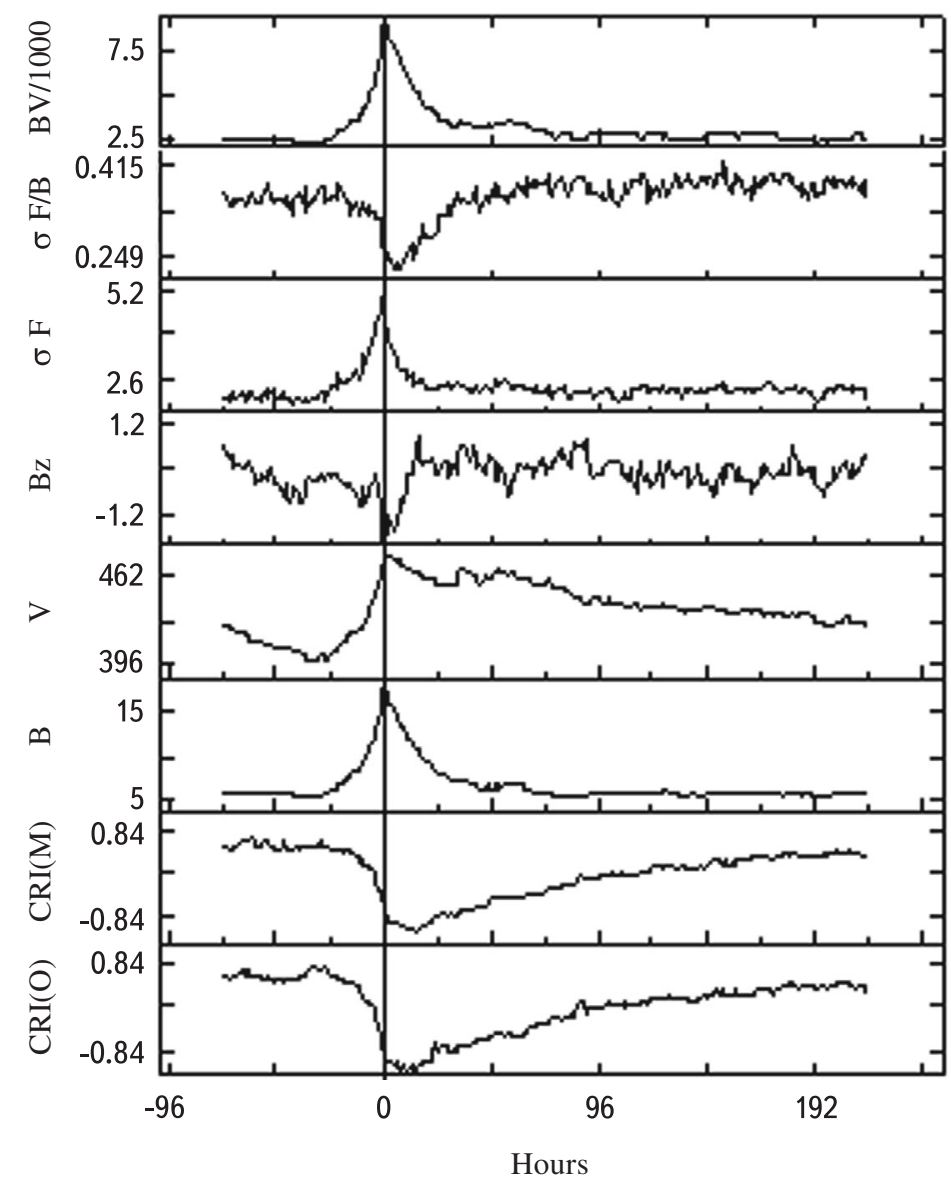

Fig.1c. Superposed epoch analysis results of hourly neutron monitor data of Oulu [CRI $(\mathrm{O})(\%)]$ and Moscow [CRI(M) (\%)] stations, magnetic field [B (nT)], solar wind velocity $\left[\mathrm{V}\left(\mathrm{km} \mathrm{s}^{-1}\right)\right]$, north-south component of magnetic field $[\mathrm{Bz}(\mathrm{nT})]$, sigma in magnetic field vector [Sigma $\mathrm{F}$ (nT)], normalized Sigma F [Sigma F/B] and interplanetary electric field $[\mathrm{BV} / 1000(\mathrm{mV} / \mathrm{m})]$ during the passage of shock-associated magnetic clouds observed in the solar cycle 23 \& 24 (1996-2018); Epoch (zero time) corresponds to time of maximum field strength (B-max). 


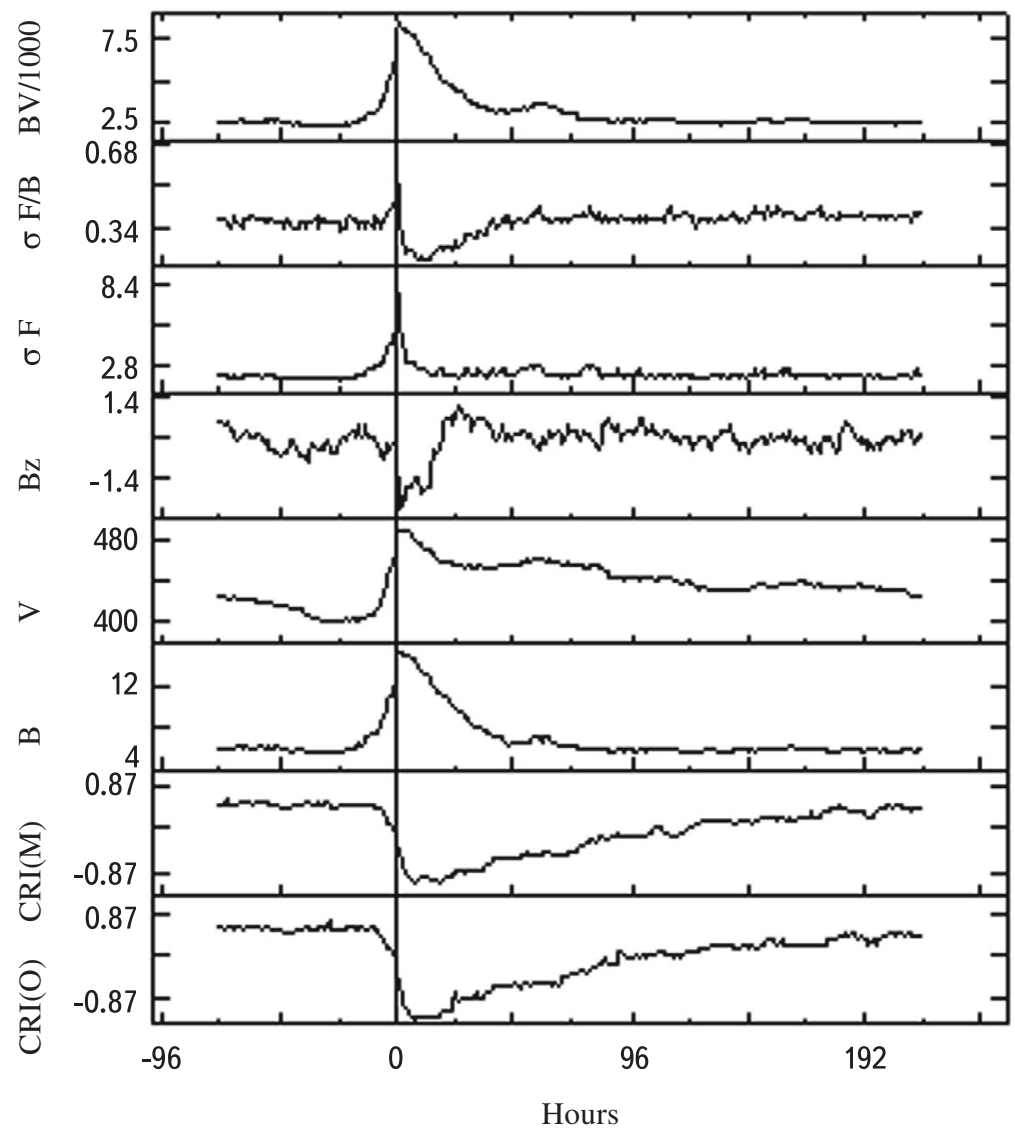

Fig.1d. Superposed epoch analysis results of hourly neutron monitor data of Oulu [CRI(O) (\%)] and Moscow [CRI(M) (\%)] stations, magnetic field [B (nT)], solar wind velocity [V $\left.\left(\mathrm{km} \mathrm{s}^{-1}\right)\right]$, north-south component of magnetic field [Bz $\left.(\mathrm{nT})\right]$, sigma in magnetic field vector [Sigma F(nT)], normalized Sigma $\mathrm{F}$ [Sigma F/B] and interplanetary electric field $[\mathrm{BV} / 1000$ $(\mathrm{mV} / \mathrm{m})]$ during the passage of shock-associated magnetic clouds observed in the solar cycle 23\&24 (1996-2018); Epoch (zero time) corresponds to time of $\sigma \mathrm{F}$ maximum. 


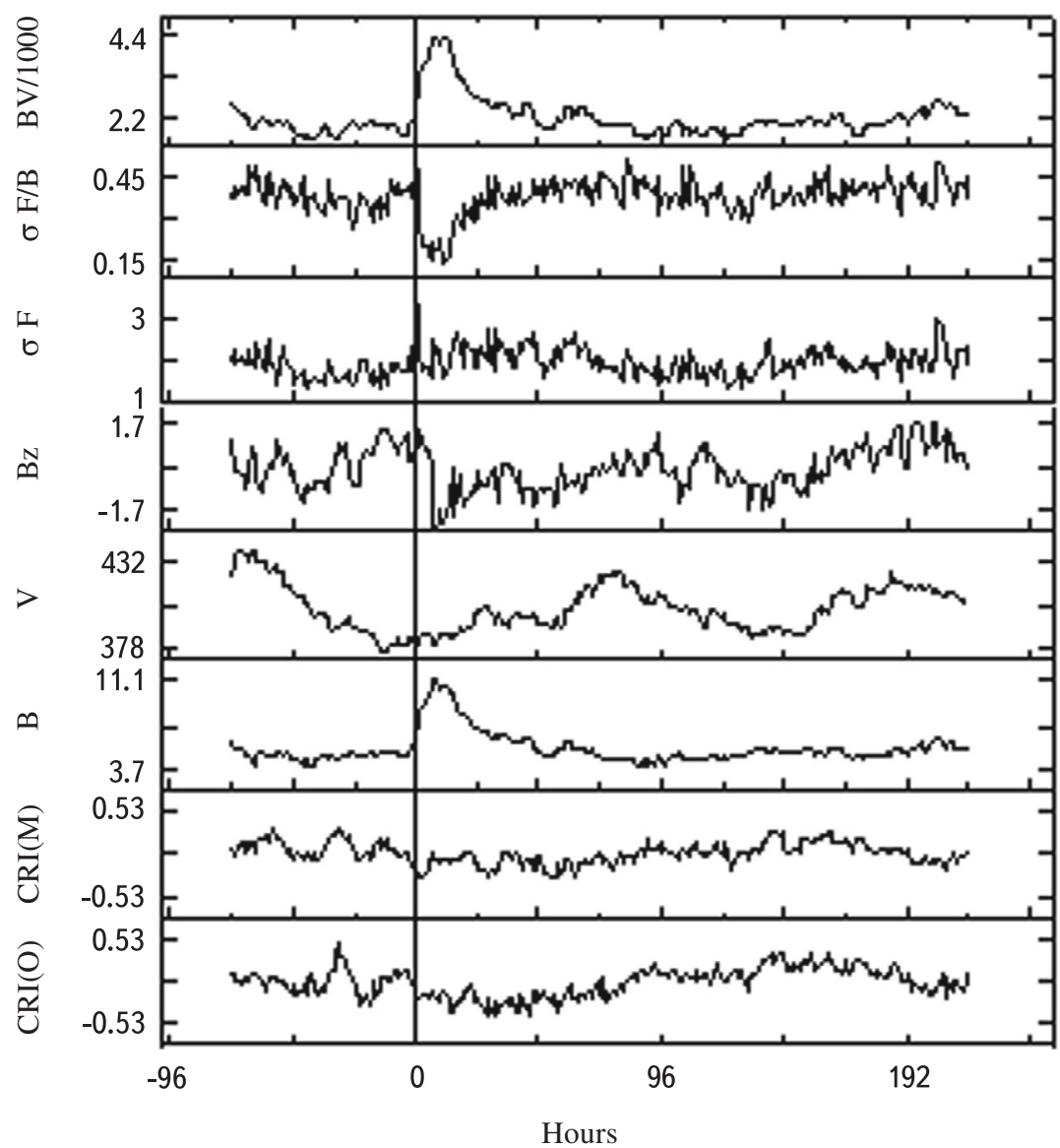

Fig.2a. Superposed epoch analysis results of cosmic ray and plasma/ field data during the passage of MCs not associated with shock observed during the solar cycle 23\&24 (1996-2018); Epoch (zero time) corresponds to start time of $\mathrm{MC}$. 


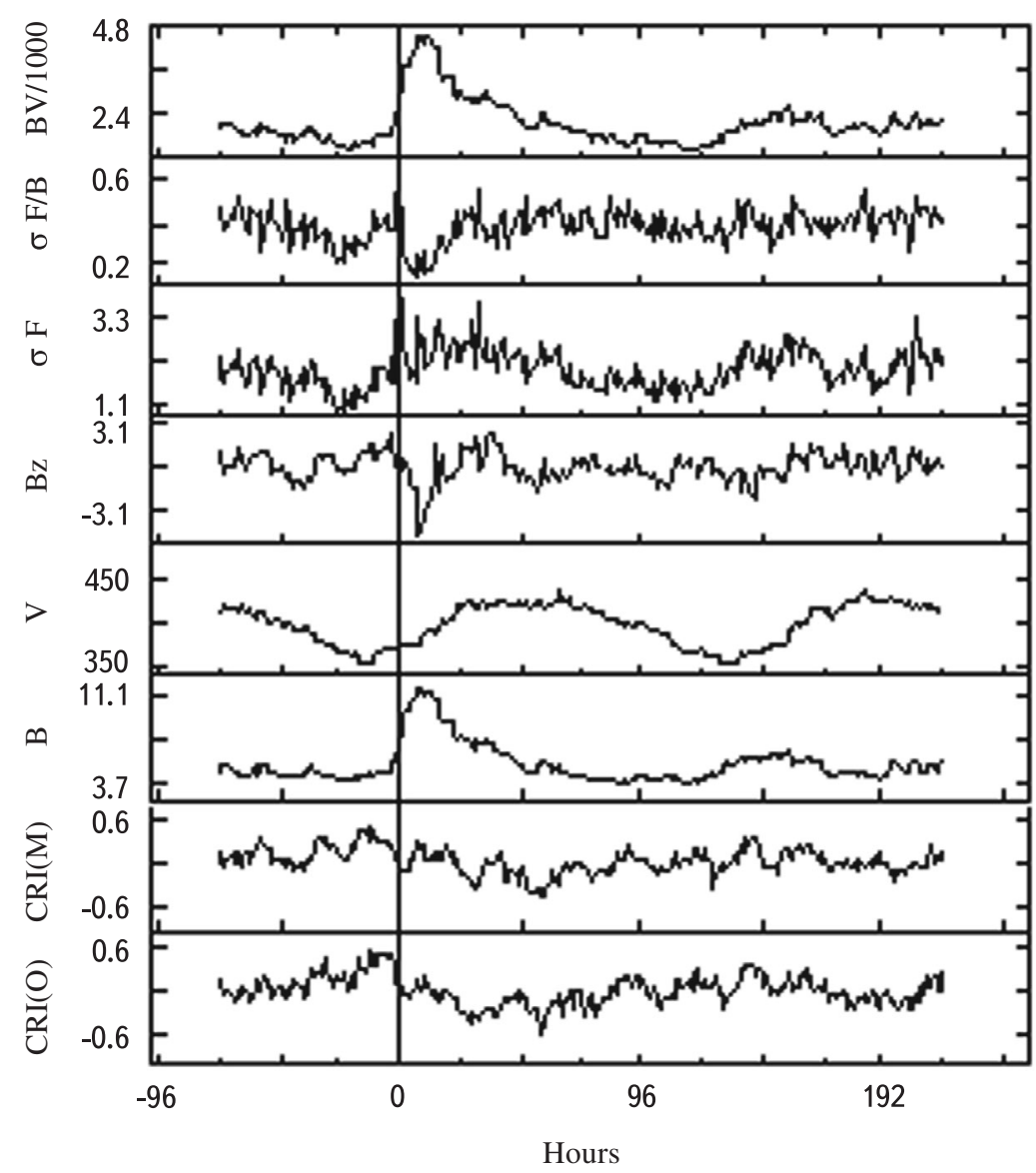

Fig.2b. Superposed epoch analysis results of cosmic ray and plasma/field data during the passage of MCs not associated with shock and followed by high-speed solar wind streams observed during the solar cycle 23\&24 (1996-2018); Epoch (zero time) corresponds to start time of MC. 


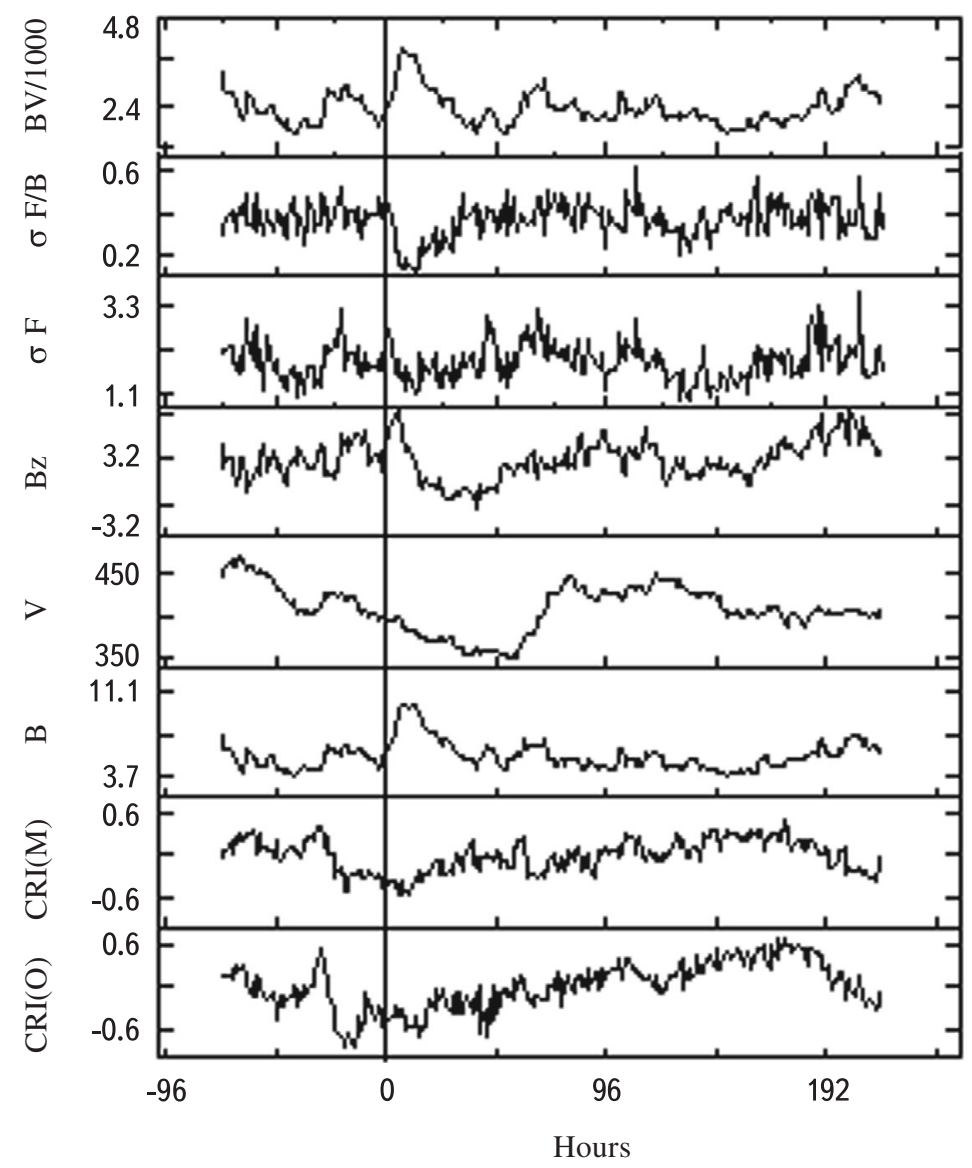

Fig.2c. Superposed epoch analysis results of cosmic ray and plasma/field data during the passage of MCs not associated with shock and not followed by high-speed solar wind streams observed during the solar cycle 23\&24 (1996-2018); Epoch (zero time) corresponds to start time of MC. 
TABLE 1. The Average Magnitude of CRI Decrease (\%) and Maximum Value of Different Parameters During the Passage of MSC and Associated Structures of Solar Cycle 23\&24 Obtained from the Superposed Epoch Plots

\begin{tabular}{|c|c|c|c|c|c|c|c|c|c|}
\hline \hline S.No. & Structure & {$[\mathrm{CRI}(\mathrm{O})]$} & {$[\mathrm{CRI}(\mathrm{M})]$} & {$[\mathrm{B}]_{\max }$} & {$[\mathrm{V}]_{\max }$} & {$[-\mathrm{Bz}]_{\min }$} & {$[\sigma \mathrm{F}]_{\max }$} & {$[\sigma \mathrm{F} / \mathrm{B}]_{\max }$} & {$[\mathrm{BV} / 1000]_{\max }$} \\
\hline 1 & $\begin{array}{c}\text { MCs associated } \\
\text { with shock }\end{array}$ & 2.050 & 1.783 & 14.099 & 496.491 & -2.084 & 6.340 & 0.511 & 7.510 \\
\hline 2 & $\begin{array}{c}\text { MCs not-associated } \\
\text { with shock }\end{array}$ & 0.505 & 0.493 & 11.118 & 403.333 & -2.002 & 3.263 & 0.486 & 4.288 \\
\hline 4 & $\begin{array}{c}\text { MCs not-associated } \\
\text { with shock and } \\
\text { followed by HSSWS }\end{array}$ & 0.592 & 0.623 & 11.890 & 404.254 & -5.097 & 3.677 & 0.523 & 4.557 \\
\hline $\begin{array}{c}\text { MCs not-associated } \\
\text { with shock and } \\
\text { not-followed } \\
\text { by HSSWS }\end{array}$ & 0.578 & 0.339 & 10.153 & 396.798 & -3.540 & 2.727 & 0.448 & 3.926 \\
\hline
\end{tabular}



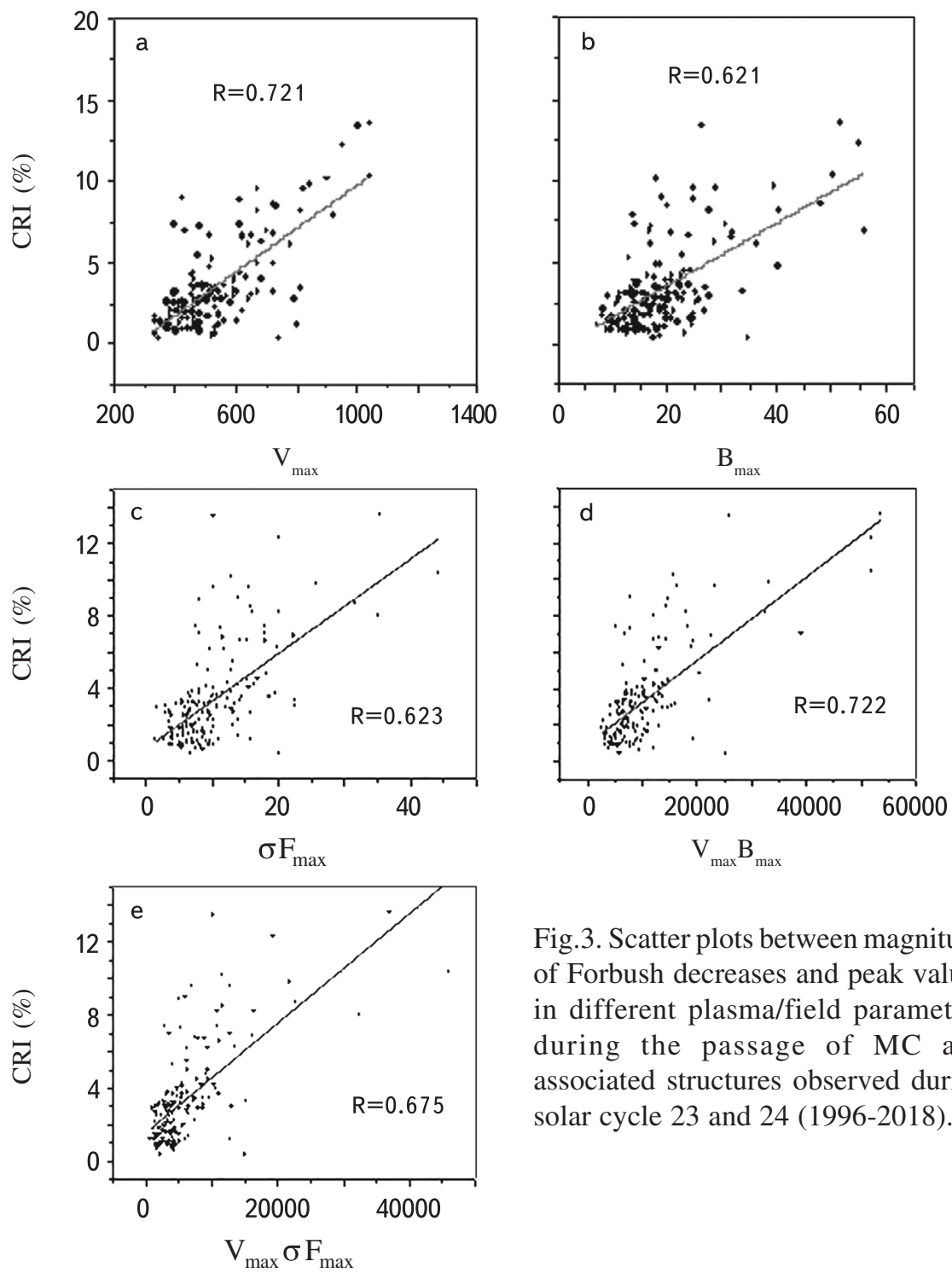

Fig.3. Scatter plots between magnitude of Forbush decreases and peak values in different plasma/field parameters during the passage of $\mathrm{MC}$ and associated structures observed during solar cycle 23 and 24 (1996-2018). 